\title{
Neurofibromatosis 1 With Arnold-Chiari Type 1 Malformation
}

\author{
Ayse Serap Karadag ${ }^{\mathrm{a}}$, Emin Ozlu ${ }^{\mathrm{a}, \mathrm{b}}$, Necmettin Akdeniz ${ }^{\mathrm{a}}$, Tugba Kevser Uzuncakmak ${ }^{\mathrm{a}}$, \\ Ozge Akbulak ${ }^{\mathrm{a}}$, Burce Can Kuru ${ }^{\mathrm{a}}$, Mukaddes Kavala ${ }^{\mathrm{a}}$
}

\begin{abstract}
Neurofibromatosis type 1 (NF-1) is the most common neurocutaneous syndrome. Even though it is often associated with a wide variety of central nervous system (CNS) dysplasias, the association with Arnold-Chiari type 1 malformation is unusual. Herein, we describe a patient with both NF-1 and Chiari type 1 malformation.
\end{abstract}

Keywords: Neurofibromatosis 1; Arnold-Chiari type 1 malformation

\section{Introduction}

Neurofibromatosis type 1 (NF-1) is a hereditary disease with autosomal dominant (AD) trait, and has an increased prevalence of various benign and malignant tumors. Major dermatological findings of NF-1 are cafe au lait spots, neurofibromas, and axillary freckles whereas various findings like Lisch nodule, optic glioma, bonny and cerebral dysplasias can create the systemic findings of this disease. Chiari malformation $(\mathrm{CM})$ is a rare congenital anomaly which is characterized by herniation of cerebellar tonsills through the foramen magnum [1]. Neurological involvement can present itself with learning difficulties, and attention disorder is the neurological involvement which can further be accompanied with different types of malignancies like malignant peripheral nerve sheath tumors, menengiomas, and ependymomas [1]. There are few cases in literature about the NF-1 and CM combination.

\section{Case Report}

A 22-year-old female patient presented to our clinic with com-

\section{Manuscript accepted for publication October 13, 2015}

aDepartment of Dermatology, Goztepe Research and Training Hospital, Istanbul Medeniyet University, Istanbul, Turkey

${ }^{b}$ Corresponding Author: Emin Ozlu, Department of Dermatology, Goztepe Research and Training Hospital, Istanbul Medeniyet University, Istanbul, Turkey. Email: dermatologg@gmail.com

doi: http://dx.doi.org/10.14740/jnr358e plaints of brownish macules and skin-colored polypoid tumors located on her trunk and extremities (Fig. 1). Brownish macules first appeared on her trunk at the age of 2 and the skincolored polypoid nodules appeared at the age of 9 . Her both lesions had increased in number in time, spreading to the extremities and other sites of the body. Also, she complained of numbness in her hands for the last 2 years.

Her dermatological examination revealed many brownish macules located on bilateral upper and lower extremities and antero-posterior of the trunk. These macules were $1-10$ $\mathrm{cm}$ in diameter, sharply demarcated, and oval to circular in shape. There was no pathological findings in her complete blood count and other routine biochemical tests. The patient's past medical history was not remarkable. The histopathologic evaluation of the biopsy specimen which was taken from one of the nodules resulted as neurofibroma (Fig. 2). The patient was diagnosed with NF-1 based on the clinical and histopathological findings. Therefore, we consulted the patient to the opthalmology, ear-nose-throat, and orthopedy departments, respectively, but no specific finding was observed in neither of clinical examinations and other tests. We also consulted the patient to the neurology department since she had been feeling numbness in her hands for 2 years. In addition, she had back pain, so cranial and spinal magnetic resonance imaging (MRI)

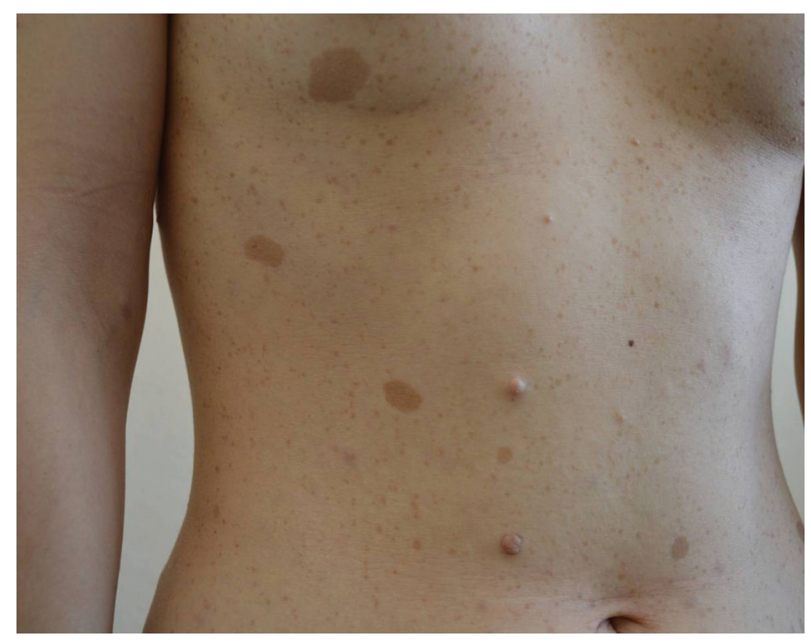

Figure 1. Multiple brownish macules and skin-colored polypoid tumors located on the anterior trunk. 


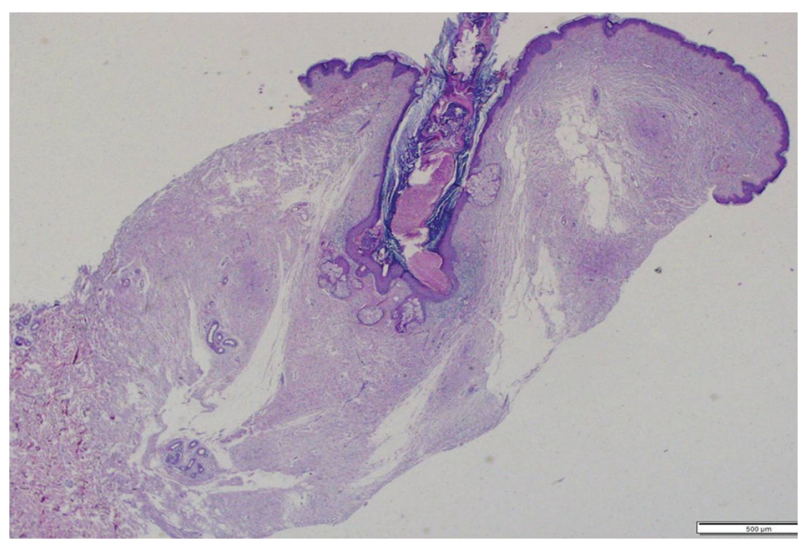

Figure 2. Histologically, there were hyperkeratosis, acanthosis and spindle cell proliferation in upper dermis to the middle dermis (H\&E, $\times 10)$.

tests were performed. Her neurological examination and cranial MRI findings were normal. However, her cervical spinal MRI exhibited CM type 1 anomaly (Fig. 3). With this new diagnosis, we consulted our patient to the neurosurgery department, and they recommended close follow-up in return.

\section{Discussion}

$\mathrm{NF}$ is an $\mathrm{AD}$, hereditary disease which primarily involves the skin, nervous system and the eyes. It has two main subtypes as NF-1 and NF-2 [1].

Cafe au lait spots, multiple neurofibromas, and Lisch nodules in the iris form the classical triad of the NF-1. In addition to these anomalies such as axillary freckling, optic gliomas, tibial pseudoarthrosis, kyphoscoliosis, sphenoid dysplasia, pectus excavatum, genu varum, macrocephaly, vascular dysplasias, and seizures, learning difficulties and mental retardation may accompany with NF-1 [2].

The diagnosis of NF-1 is made according to the criteria defined by the National Institutes of Health (NIH). Presence of two or more criteria is enough for the diagnosis. These criteria are: 1) six or more cafe au lait spots, prepubertal $>5 \mathrm{~mm}$, postpubertal $>15 \mathrm{~mm}$ in diameter, at least six in number; 2) multiple neurofibromas or plexiform neurofibroma; 3) axillary and inguinal freckling; 4) optic glioma; 5) Lisch nodules in iris; 6) skeletal anomalies like thinning of long bone cortex or sphenoid dysplasia; and 7) positive family history [3].

Cognitive dysfunction and difficulty in learning are reported in $40-60 \%$ of NF-1 patients. Although difficulty in learning and cognitive dysfunction are frequently present, epileptic seizures and mental retardation are not common [4]. Mental retardation or cognitive dysfunction were not observed in our patient. Few cases that are associated with CM have been reported in recent years [5-7].

$\mathrm{CM}$ is a congenital anomaly characterized by displacement of posterior fossa structures in different angles, to the upper cervical spinal canal through the foramen magnum. CM consists of four subtypes classically. These are: 1) CM type 1 (simple form); 2) CM type 2 (accompanied by spinal dys-

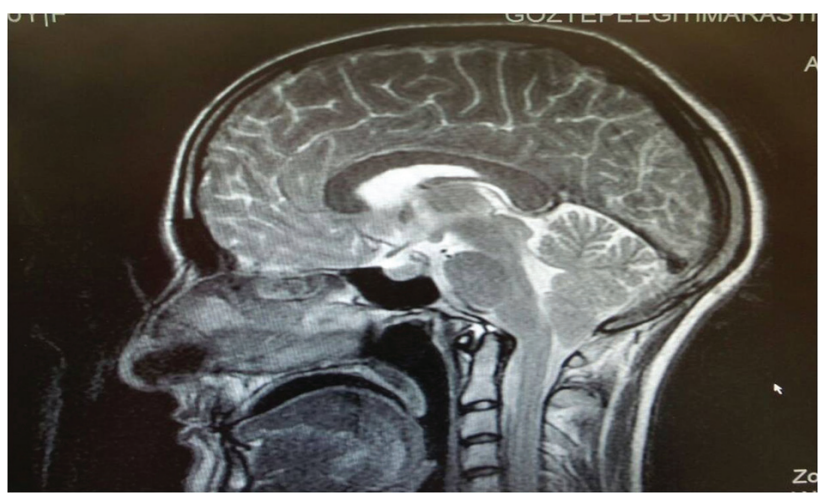

Figure 3. Cervical spinal magnetic resonance imaging revealed Chiari type 1 malformation.

rafism); 3) CM type 3 (accompanied by craniocervical herniation); and 4) CM type 4 (characterized with severe cerebellar dysplasia) [8].

CM type 1 is the simplest form among all the CM types and is usually sporadic. CM type 1 is more commonly seen in third to fourth decades and more common in women [9]. In CM type 1 , clinical findings occur due to the compression of cerebellar tonsils by the neural and dural structures. Headache is the most common symptom in CM type 1, but symptoms such as fatigue, sensory dysfunction, and nystagmus can also be present [9]. Patient had feeling of numbness in hands in our case.

In literature, the association of NF-1 with CM type 1 has been previously rarely described. Afifi et al were the first to report two cases with this association [5]. Battisella et al reported this association and suggested that CM-1 should be accepted as one of the central nervous system (CNS) anomalies seen in NF-1 [6]. Fernandez et al reported a case with syringomyelia in addition to NF-1 and CM-1 [7]. Then, Herrero et al reported a case with headache in addition to NF-1 and CM-1 [10].

As a result, NF-1 is an AD neurocutaneous disease which is characterized by skin, eye and CNS involvement on its course. Even though NF-1 is a rare syndrome, it should be kept in mind that anomalies such as CM-1 may also accompany with this syndrome and therefore, especially CNS should be evaluated with diagnostic imaging modalities.

\section{Conflicts of Interest}

There are no conflicts of interest among all authors regarding this article.

\section{References}

1. Felicio AC, Godeiro-Junior Cde O, Borges V, Silva SM, Ferraz HB. Hemifacial spasm in a patient with neurofibromatosis and Arnold-Chiari malformation: a unique case association. Arq Neuropsiquiatr. 2007;65(3B):855857.

2. Riccardi VM. Neurofibromatosis. Neurol Clin. 1987;5(3):337-349. 
3. Gutmann DH, Aylsworth A, Carey JC, Korf B, Marks J, Pyeritz RE, Rubenstein A, et al. The diagnostic evaluation and multidisciplinary management of neurofibromatosis 1 and neurofibromatosis 2. JAMA. 1997;278(1):5157.

4. Gutmann DH. Recent insights into neurofibromatosis type 1: clear genetic progress. Arch Neurol. 1998;55(6):778780 .

5. Afifi AK, Dolan KD, Van Gilder JC, Fincham RW. Ventriculomegaly in neurofibromatosis-1. Association with Chiari type I malformation. Neurofibromatosis. 1988;1(56):299-305.

6. Battistella PA, Perilongo G, Carollo C. Neurofibromato- sis type 1 and type I Chiari malformation: an unusual association. Childs Nerv Syst. 1996;12(6):336-338.

7. Fernandez-Jaen A, Calleja-Perez B, Pascual-Castroviejo I. [Syringomyelia, Chiari's malformation and scoliosis in a patient with type 1 neurofibromatosis]. An Esp Pediatr. 1998;48(5):522-524.

8. Isik N. Chiari Malformasyonlari ve Siringomiyeli. Turk Norosirurji Dergisi. 2013;23(2):185-194.

9. Steinbok P. Clinical features of Chiari I malformations. Childs Nerv Syst. 2004;20(5):329-331.

10. Herrero Valverde A, Moiron Simoes R, Mera Campillo $\mathrm{J}$, Palma T. [Headache in patient with neurofibromatosis type 1]. Neurologia. 2007;22(10):911-914. 